\title{
Análisis de la experiencia pedagógica: Campamento EXPLORA Chile VA! Valorando la Biodiversidad Maulina
}

Analysis of teaching experience: Camp EXPLORA Chile Va! Valuing Biodiversity Maulina

\author{
Volumen 17, Número 1 \\ Enero-Abril
}

pp. 1-25

\author{
Marta Fuentealba Cruz \\ Felipe Marín Isamit \\ Franklin Castillo Retamal \\ Lisandro Roco Fuentes
}

Revista indizada en REDALYC, $\underline{\text { SCIELO }}$

Revista distribuida en las bases de datos:

LATINDEX, DOAJ, REDIB, IRESIE, CLASE, DIALNET, SHERPA/ROMEO, QUALIS-CAPES, MIAR

Revista registrada en los directorios:

ULRICH'S, REDIE, RINACE, OEI, MAESTROTECA, PREAL, CLACSO 


\title{
Análisis de la experiencia pedagógica: Campamento EXPLORA Chile VA! Valorando la Biodiversidad Maulina \\ Analysis of teaching experience: Camp EXPLORA Chile Va! Valuing Biodiversity Maulina
}

\author{
Marta Fuentealba Cruz \\ Felipe Marín Isamit ${ }^{2}$ \\ Franklin Castillo Retama/ ${ }^{3}$ \\ Lisandro Roco Fuentes ${ }^{4}$
}

\begin{abstract}
Resumen: El objetivo del presente trabajo fue analizar el impacto de la iniciativa "Campamento EXPLORA Chile VA!: Valorando la Biodiversidad Maulina", en la valoración de la ciencia, la protección del patrimonio natural y el aporte al desarrollo sustentable entre los chilevanenses (estudiantes participantes). Para lo cual, después de seis días de campamento y vivir experiencias en terreno, se enfrentaron a desafíos para resolver en equipo, realizar experiencias en laboratorios naturales, conocer historias de jóvenes emprendedores y sostener conversaciones con científicos que han hecho importantes contribuciones que han ayudado a comprender la biodiversidad del Maule. Se aplicó una encuesta de impacto (día 6) a los 96 chilevanenses, la cual se comparó con la encuesta de expectativas ejecutada el primer día. Las preguntas abiertas fueron analizadas mediante el software Atlas ti. Las bitácoras diarias se analizaron a través de la técnica de nube de conceptos. Se confirmó una adecuada consistencia interna de la prueba de expectativas $(\alpha$ Cronbach $=0,8530)$ y del examen de impacto $(\alpha$ Cronbach $=$ 0,8256). Se detectó que el campamento sirvió para que todos los participantes, independiente de su procedencia socioeducativa, descubrieran, desarrollaran e incrementaran habilidades potenciando su desarrollo integral, actitudes y/o competencias para las necesidades reales de grupos socioeducativos muy diversos, como son los de dependencia municipal y particular. Desde la perspectiva del análisis cuantitativo, se concluyó que más del 88 $\%$ de los chilevanenses declaró mantener o incrementar su valoración por la ciencia, la protección del patrimonio natural y el aporte al desarrollo sustentable.
\end{abstract}

Palabras clave: educación ambiental, sustentabilidad, biodiversidad, ciencia.

Abstract: The aim of this study was to evaluate the impact of the "EXPLORE Chile Va! Camp: Maulina Valuing Biodiversity" in the valuation of science, protection of natural heritage and contribution to sustainable development among chilevanenses (participating students). For that, after six days of camp and live experiences on the ground, face challenges to solve in teams, perform experiments in natural laboratories, known stories of young entrepreneurs and talks with scientists who have made significant contributions to help understand the biodiversity of the Maule; Impact test (day 6) to 96 chilevanenses, which was compared with expectations test applied on the first day was applied. Open questions were analyzed using the Atlas ti software. The daily logs analyzed by the technique of cloud concepts. Adequate internal consistency expectations test (Cronbach $\alpha=0.8530$ ) and impact test (Cronbach $\alpha=0.8256$ ) was confirmed. It was found that the camp served to all participants, regardless of their socio-educational source, discover, develop and increase skills promoting their development as it allowed develop skills, attitudes and / or skills to the real needs of very diverse socio-educational groups, as those of municipal and private agency. From the perspective of quantitative analysis, we conclude that over $88 \%$ of the declared chilevanenses maintain or increase its appreciation for science, protection of natural heritage and contribution to sustainable development.

Keywords: environmental education, sustainability, biodiversity, science.

\footnotetext{
1 Profesor Adjunto de la Universidad Católica del Maule, Chile. Directora Proyecto CHVA010002. Dirección electrónica: mfuentea@ucm.cl

2 Profesor Auxiliar de la Universidad Católica del Maule, Chile. Coordinador de contenidos de emprendimiento Proyecto CHVA010002. Dirección electrónica: fmarin@ucm.cl

${ }^{3}$ Profesor Auxiliar de la Universidad Católica del Maule, Chile. Jefe de campamento Proyecto CHVA010002. Dirección electrónica: fcastillo@ucm.cl

4 Profesor Auxiliar de la Universidad Católica del Maule, Chile. Coordinador de contenidos científicos Proyecto CHVA010002. Dirección electrónica: Iroco@ucm.cl
}

Artículo recibido: 8 de marzo, 2016

Enviado a corrección: 27 de junio, 2016

Aprobado: 21 de noviembre, 2016 


\section{Introducción}

El tema del Campamento EXPLORA Chile VA! fue la valoración de la biodiversidad maulina, debido a que, en un país como Chile, el cual sustenta su economía en la extracción de materias primas, la conservación de la biodiversidad es fundamental, pues no es posible vincular desarrollo cultural y económico sin una conciencia mínima de conservación y protección del entorno en donde se vive y que otorga los recursos para subsistir (Baquedano, 2008; Castillo y Fuentealba, 2014; Goleman, 2009; Zúñiga y Fuentealba, 2001). El uso no sustentable y el consumo excesivo de los recursos naturales nos ha llevado a generar degradación ambiental y pérdida de la biodiversidad.

Tikka, Kuitunen y Tynys (2000) señalan que la crisis medioambiental que viven muchos países se debe fundamentalmente al comportamiento y a los patrones de pensamiento de las personas; de esta manera, las mayores soluciones a los problemas de esta índole pasan por una modificación del comportamiento humano, por lo que es necesaria una estrategia de educación que logre un equilibrio entre el individuo y la naturaleza, fomentando el desarrollo de las ciencias y la conciencia ambiental entre las nuevas generaciones (Fuentealba, 2011, 2014; Mendieta y Gutiérrez, 2014; Sosa, Isaac-Márquez, Eastmond, Ayala y Arteaga, 2010).

De esta forma, la educación, entendida como agente de cambio y transformación social, adquiere un rol preponderante para generar y promover cambios, a través del desarrollo de habilidades blandas y habilidades cognitivas. Así, la educación ambiental se presenta como una alternativa para generar valores que se traducen en conductas y actitudes favorables para promover el desarrollo equilibrado en armonía con el entorno circundante, incrementando capacidades plenas en las diversas dimensiones del ser humano; es decir, intelectual, moral y espiritualmente, lo que irremediablemente se reflejará en el ámbito actitudinal de las personas (Fuentealba, 2011, 2014; Mendieta y Gutiérrez 2014; Ministerio del Medio Ambiente, 2009; Monroe y Fien, 2005).

De acuerdo con lo anterior, se espera que los chilevanenses, a través de visitas a procesos productivos asociados a recursos naturales renovables, acrecenten vocaciones científicas tecnológicas. Además, incrementen su valoración de la ciencia y la tecnología, al aumentar el compromiso con el desarrollo sustentable de la región; y que mediante reflexiones y visitas a áreas silvestres protegidas, aumenten la valoración del patrimonio natural local. Por estos motivos, el objetivo del presente trabajo es evaluar el impacto de la iniciativa Campamento EXPLORA Chile VA!: Valorando la Biodiversidad Maulina, en la 
valoración de la ciencia, la protección del patrimonio natural y el aporte al desarrollo sustentable entre los chilevanenses.

\section{Referente teórico}

La educación no formal incluye diversos programas didácticos específicos; tales como los campamentos, que pueden ser utilizados para contribuir a la formación de los estudiantes (Duarte, 2003; Vasconcelos y Praia, 2005). Así, el campamento es un programa didáctico de la educación no formal, entendido como toda experiencia de enseñanza y aprendizaje previamente planificada con objetivos, contenidos, metodologías y actividades que se realizarán en tiempo y espacios preseleccionados, con la participación de una población de beneficiarios que comparten ciertas características demográficas, socioeconómicas e intereses temáticos; donde se posibilita e impulsa un diseño didáctico que facilita el aprendizaje vivencial y lúdico, al dar especial importancia a la orientación pedagógica de cada una de las actividades (Luján y Rodríguez, 2011).

Es importante considerar que, en el transcurso del campamento, muchas actividades se ejecutan directamente en contacto con la naturaleza, las que, por su biogeoestructura, brindan un ambiente de incertidumbre, en las cuales se puede optar no solo por un sinfín de respuestas motoras, sino que además ofrecen lo propicio para el autoconocimiento, de esta forma, el estudiante tiene las posibilidades de ir construyendo habilidades, actitudes, valores y conocimientos en forma directa y espontáneamente (Ascaso, 1996; Castillo, 2011, 2015; Guillén, Lapetra y Casterad, 2000).

El Campamento EXPLORA Chile VA! es una iniciativa del eje de valoración del Programa EXPLORA de la Comisión Nacional de Investigación Científica y Tecnológica (CONICYT-Chile), que promueve el desarrollo de capital humano, al mostrar al estudiantado de $2^{\text {do }}$ y $3^{\text {er }}$ año de educación media la nueva configuración social y económica del siglo XXI, para que, a través de las prácticas emprendedoras, diseñen un proyecto de vida y se vinculen con la ciencia y la tecnología. Todas las actividades de esta iniciativa están orientadas a producir una transformación en la actitud de los jóvenes, producir interés y motivación por la ciencia (CONICYT, 2014). 


\section{Metodología}

El Campamento EXPLORA Chile Va! se llevó a cabo en Termas de Quinamavida, emplazada en la precordillera de Linares, región del Maule, Chile (3578’Lat. - $71^{\circ} 43^{\prime}$ Long. a 373 m.s.n.m.), en diciembre de 2014, donde se realizaron diversas actividades experimentales, utilizando el entorno como laboratorio natural. Durante 6 días de campamento, los jóvenes participaron en actividades destinadas a reforzar habilidades de experimentación, indagación, creatividad, liderazgo, trabajo en equipo, emprendimiento e incrementar su autoestima. Por un lado, las tareas científicas estuvieron enfocadas a temáticas medioambientales de conocimiento y reconocimiento del entorno; estas contemplaron charlas, conversaciones con profesionales en las ciencias, encuentros cercanos en instalaciones industriales que procesan recursos naturales, reconocimiento de especies en visitas a áreas silvestres protegidas, campaña de forestación, entre otras. Por otro lado, las labores de emprendimiento se implementaron buscando el desarrollo de habilidades personales y sociales, además de una actitud favorable en torno a la protección del medioambiente y la biodiversidad. Se buscó la integración de la teoría, aspectos prácticos y éticos al articular los ejes científico y de emprendimiento en el desarrollo del campamento.

\subsection{Tipo de investigación}

La investigación es un estudio mixto que permite integrar metodologías cuantitativas y cualitativas, con el propósito de que exista mayor comprensión del objeto de estudio (Cook y Reichardt, 2004; Pereira-Pérez, 2011). No se realizó ninguna manipulación sobre el estudiantado al aplicar el instrumento; en este sentido, la importancia presentada por el estudio es que permite tener una mayor validez externa, lo que posibilita la generalización de los resultados a otros individuos (Hernández, Fernández y Baptista, 2010).

\subsection{Muestra}

El grupo de estudio consistió en 96 estudiantes de ambos sexos, provenientes de 17 comunas de la región del Maule, de un rango de edad de 14 a 16 años, quienes cursaban entre segundo y tercer año de estudios secundarios, representando a 43 establecimientos educacionales de todas las dependencias administrativas (municipal, subvencionado y particular). El grupo de estudio fue seleccionado de un universo de 680 estudiantes que postularon al Campamento EXPLORA Chile VA! vía concurso, a través de la página web de 
la Universidad Católica del Maule, considerando la representatividad de la región del Maule, dependencia del establecimiento educacional y sexo de los participantes, por lo cual no fue probabilístico.

\subsection{Instrumento}

Para evaluar el cumplimiento del objetivo, a los 96 chilevanenses se les aplicó encuestas de expectativas (pruebas de entrada) e impacto (pruebas de salida), las cuales fueron validadas por un panel de expertos (6) a través del método Delphi (Bravo y Arrieta, 2005; Fernández y López, 2013). Estas contenían preguntas cerradas categorizadas en la forma de escala de Likert y preguntas abiertas.

Las respuestas cuantitativas se miden solicitando el grado de acuerdo con cada ítem en un formato tipo Likert de 5 puntos: (1) para nada, (2) en desacuerdo, (3) más o menos, (4) de acuerdo, y (5) muy de acuerdo (Cañadas y Sánchez, 1998; Hernández y Jiménez, 2010; Ospina, Sandoval, Aristizábal y Ramírez, 2005).

\section{Análisis de los datos}

Por un lado, el análisis cuantitativo de las preguntas cerradas categorizadas se efectuó con estadística descriptiva. Por otro lado, la comparación de las encuestas de entrada y salida se hizo mediante el examen t-student. Asimismo, la confiabilidad de las encuestas se midió a través del a de Cronbach; para lo cual se utilizó el software Statistical Package for Social Science versión 15.0.

Las preguntas abiertas fueron estudiadas mediante el software Atlas.ti, paquete informático que tiene como objetivo facilitar el análisis de grandes volúmenes de datos de texto (Andreu, García-Nieto y Pérez, 2007; García 2003; San Martín, 2014), para lo cual se realizó un reducción de datos estableciendo relaciones entre conceptos, generando códigos, lo que implicó redactar una lista con todos los conceptos, interpretaciones, tipologías y proposiciones que se identificaron para las respuestas de cada pregunta (Tabla 1), lo que permitió visualizar la variabilidad de la percepción de los chilevanenses en relación con los objetivos del Campamento EXPLORA Chile Va!. 
Tabla 1

Asignación de códigos por preguntas

\begin{tabular}{|c|c|c|}
\hline & Preauntas & Códiao/Categoría \\
\hline \multirow[t]{2}{*}{$\begin{array}{l}\text { Ingreso } \\
\text { (Expectativa) }\end{array}$} & $\begin{array}{l}\text { ¿Cómo te imaginas el Campamento } \\
\text { CHILE VA!? ¿Por qué? }\end{array}$ & $\begin{array}{l}\text { (i) Aprendizaje científico } \\
\text { (ii) Desarrollo personal } \\
\text { (iii) Desarrollo social } \\
\text { (iv) General: entretención, recreación, } \\
\text { aprender }\end{array}$ \\
\hline & $\begin{array}{l}\text { ¿Qué es lo que te haría más feliz } \\
\text { como resultado de esta experiencia? }\end{array}$ & $\begin{array}{l}\text { (i) Aprendizaje científico } \\
\text { (ii) Aspectos generales } \\
\text { (iii) Crecimiento personal } \\
\text { (iv) Vínculos sociales }\end{array}$ \\
\hline \multirow[t]{3}{*}{$\begin{array}{l}\text { Salida } \\
\text { (Impacto) }\end{array}$} & $\begin{array}{l}\text { En general, ¿cómo evalúas este } \\
\text { Campamento CHILE VA!? }\end{array}$ & $\begin{array}{l}\text { (i) Valoración de la experiencia en } \\
\text { general } \\
\text { (ii) Valoración de la interacción social } \\
\text { (iii) Valoración de la organización y } \\
\text { equipo } \\
\text { (iv) Valoración del aprendizaje científico } \\
\text { (v) Valoración del desarrollo personal }\end{array}$ \\
\hline & $\begin{array}{l}\text { ¿Qué significó CHILE VA! para ti? } \\
\text { ¿Con qué te vas? }\end{array}$ & $\begin{array}{l}\text { (i) Aprendizaje científico } \\
\text { (ii) Desarrollo personal } \\
\text { (iii) Generación de vínculos } \\
\text { (iv) Positivo en general }\end{array}$ \\
\hline & $\begin{array}{l}\text { ¿Cómo implementarás lo vivido y } \\
\text { aprendido en CHILE VA! a tu vida? } \\
\text { ¿Qué crees que cambiará? }\end{array}$ & $\begin{array}{l}\text { (i) Plano científico ambiental } \\
\text { (ii) Plano general } \\
\text { (iii) Plano individual } \\
\text { (iv) Plano social }\end{array}$ \\
\hline
\end{tabular}

Fuente: Elaboración propia de los autores (2016).

El análisis de las bitácoras se efectuó mediante la técnica de nube de conceptos.

\section{Resultados}

\subsection{Características de la muestra}

La Tabla 2 presenta la caracterización de la muestra. Se observa una mayor participación de estudiantes del género masculino, de segundo medio, y provenientes de colegios municipales.

Tabla 2

Características generales de la muestra

\begin{tabular}{|c|c|c|}
\hline \multicolumn{2}{|c|}{ Variable } & $\%$ \\
\hline Género & $\begin{array}{l}\text { Femenino } \\
\text { Masculino }\end{array}$ & $\begin{array}{l}42.7 \\
57.3\end{array}$ \\
\hline Curso & $\begin{array}{l}\text { Segundo medio } \\
\text { Tercero medio }\end{array}$ & $\begin{array}{l}58.3 \\
41.7\end{array}$ \\
\hline Dependencia establecimiento & $\begin{array}{l}\text { Municipal } \\
\text { Subvencionado } \\
\text { Particular }\end{array}$ & $\begin{array}{l}40.6 \\
36.5 \\
22.9\end{array}$ \\
\hline
\end{tabular}

Fuente: Elaboración propia de los autores (2016). 


\subsection{Confiablidad de la muestra}

El coeficiente alfa de Cronbach, que analiza la fiabilidad de la escala de medición, fue de 0.8530 para encuesta de expectativas, y de 0.8256 para encuesta de impactos; esto demostró que los instrumentos de medición presentan una adecuada consistencia interna, por tanto, son fiables.

\subsection{Análisis cualitativo}

\subsubsection{Análisis de pregunta abiertas a través del programa ATLAS.ti}

El análisis de las preguntas abiertas, de expectativas e impactos, se realizó considerando la dependencia del establecimiento educacional, lo que está estrechamente ligado a su entorno socioeducativo. Se detectó que los chilevanenses de cada una de las dependencias presentaba características particulares que los identificaba como grupo y, a su vez, los diferenciaba de los otros dos grupos, por ejemplo, las expectativas de los jóvenes de procedencia municipal tendían al desarrollo social, mientras que quienes venían de establecimientos particulares lo hacían al incremento de su acervo científico.

Transcurridos los seis día de campamento, los de dependencia municipal valoraron considerablemente el incremento de acervo científico como parte de su desarrollo personal; en cambio, los chilevanenses de dependencia particular estiman enormemente el haber incrementado sus habilidades sociales, esto es respeto por las diferentes funciones al interior de un equipo de trabajo, sentirse parte de un conjunto, entre otros. Por estos motivos, se puede inferir que el Campamento EXPLORA Chile VA! sirvió para que todos los participantes, sin importar la dependencia del establecimiento educacional, descubrieran, desarrollaran e incrementaran habilidades y potenciaran su desarrollo integral.

A continuación, se entrega el análisis de cada una de las preguntas abiertas.

\section{Pregunta 1: ¿Cómo imaginas el Campamento Chile VA!? ¿Por qué?}

El $62 \%$ de los estudiantes de establecimientos con dependencia municipal imaginaba un campamento entretenido que ayudaría a sus aprendizajes y a desarrollar en ellos habilidades sociales en un ambiente que facilitaría el vínculo con otras personas. Con menor frecuencia, el $38 \%$ declaró percibir el campamento como un espacio de aprendizaje científico ( $19 \%$ de este $38 \%$ ) y de desarrollo personal (19\% de este $38 \%$ ).

La percepción de los estudiantes de establecimientos con dependencia particular subvencionada en un $66 \%$ apuntaba a aspectos generales; esto es imaginar un 
campamento entretenido, divertido, que contribuye con el aumento de su aprendizaje científico. Asimismo, el 34 \% de las respuestas apuntaba a aspectos de desarrollo personal y social con igual frecuencia.

Los estudiantes de establecimientos con dependencia particular, en un $57 \%$, imaginaban un campamento que contribuiría fuertemente con el aumento de su aprendizaje científico y su desarrollo de habilidades científicas; y un $24 \%$ que se beneficiaría en su desarrollo personal y académico. Con menor frecuencia, el $19 \%$, apuntó sus respuestas a percibir el campamento como un espacio donde la interacción social jugaría un papel relevante.

La Tabla 3 mostró las respuestas más destacadas entregadas por los chilevanenses de acuerdo con la dependencia del establecimiento educacional y por código.

Tabla 3

Respuestas más representativas de los chilevanenses a la pregunta ¿cómo imaginas el Campamento Chile Va!? Entre paréntesis se indica el porcentaje $(\%)$ de estudiantes que responde por dependencia del establecimiento educacional y por código

\begin{tabular}{|c|c|c|c|c|}
\hline \multirow[b]{2}{*}{ Dependencia } & \multicolumn{4}{|c|}{ Códigos } \\
\hline & $\begin{array}{l}\text { Aprendizaje } \\
\text { científico }\end{array}$ & $\begin{array}{l}\text { Desarrollo } \\
\text { personal }\end{array}$ & Desarrollo social & $\begin{array}{l}\text { General: } \\
\text { entretención, } \\
\text { recreación, } \\
\text { aprendizaje }\end{array}$ \\
\hline Municipal & $\begin{array}{l}\text { "Me imagino que } \\
\text { será un } \\
\text { campamento rico } \\
\text { en experiencias de } \\
\text { tipo informativa y } \\
\text { con muchas } \\
\text { instancias para } \\
\text { aprender más } \\
\text { sobre la ciencia, ya } \\
\text { que de eso se } \\
\text { trata". }\end{array}$ & $\begin{array}{lr}\text { "Un lugar donde } \\
\text { nos podamos } \\
\text { sentir cómodos } \\
\text { en lo que } \\
\text { hacemos y } \\
\text { aprendemos, } \\
\text { porque para } \\
\text { poder aprender } \\
\text { debemos estar } \\
\text { bien nosotros } \\
\text { mismos". }\end{array}$ & $\begin{array}{l}\text { "Una experiencia } \\
\text { nueva, llena de } \\
\text { anécdotas y } \\
\text { desafíos que se } \\
\text { podrán llevar a } \\
\text { cabo con la } \\
\text { familia designada. } \\
\text { Todo será posible } \\
\text { con trabajo en } \\
\text { equipo y buena } \\
\text { comunicación". } \\
\text { "Yo imagino el } \\
\text { campamento } \\
\text { como un espacio } \\
\text { de convivencia } \\
\text { con personas de } \\
\text { diferentes } \\
\text { realidades, donde } \\
\text { aprenderemos a } \\
\text { valorar el trabajo } \\
\text { en equipo". }\end{array}$ & $\begin{array}{lr} & \text { "Entretenido r } \\
\text { educativo porque } \\
\text { vamos a } & \text { usar } \\
\text { termas y } & \text { nos } \\
\text { quedaremos } & \text { en } \\
\text { hotel". } & \end{array}$ \\
\hline & (19\%) & (19\%) & (24\%) & (38 \%) \\
\hline
\end{tabular}




\begin{tabular}{|c|c|c|c|c|}
\hline $\begin{array}{l}\text { Particular } \\
\text { subvencionado }\end{array}$ & $\begin{array}{c}\text { "Lo imagino como } \\
\text { un lugar y espacio } \\
\text { de aprendizaje y } \\
\text { conocimiento. Un } \\
\text { lugar donde pueda } \\
\text { conocer cosas } \\
\text { nuevas } \\
\text { relacionadas con la } \\
\text { biodiversidad de la } \\
\text { región". } \\
\text { (20\%) }\end{array}$ & $\begin{array}{l}\text { "Imagino que será } \\
\text { una experiencia } \\
\text { constructiva que } \\
\text { me ayudará a } \\
\text { desarrollar un } \\
\text { gusto por las } \\
\text { ciencias". }\end{array}$ & \begin{tabular}{l} 
"Lo imagino lleno \\
de experiencias y \\
actividades, las \\
cuales r se \\
combinan ra \\
pedagogía y la \\
sociabilización \\
con otras \\
personas". \\
\multicolumn{1}{c}{$(\mathbf{1 7} \%)$}
\end{tabular} & $\begin{array}{l}\text { "Un lugar lindo por } \\
\text { sus termas y el } \\
\text { ambiente. } \\
\text { Entretenido, porque } \\
\text { la gente que está } \\
\text { es simpática". }\end{array}$ \\
\hline Particular & $\begin{array}{lr}\text { "Una actividad la } \\
\text { cual me dará la } \\
\text { oportunidad de } \\
\text { conocer ra } \\
\text { biodiversidad de mi } \\
\text { región. Didáctico, } \\
\text { porque profundiza } \\
\text { los remas } \\
\text { científicos". }\end{array}$ & \begin{tabular}{lr} 
"Me lo imagino \\
como un lugar en \\
donder podré \\
poner en práctica \\
mis habilidades y \\
donder podré \\
adquirir mayores \\
conocimientos \\
porque estaré \\
rodeado de \\
personas que \\
tienen r mis \\
mismos intereses \\
y porque aparte \\
podré tener la \\
habilidad de \\
escuchar charlas \\
de científicos \\
exitosos". \\
\multicolumn{3}{c}{ (24\%) }
\end{tabular} & $\begin{array}{l}\text { "Una experiencia } \\
\text { entretenida por } \\
\text { las actividades } \\
\text { que presenta y la } \\
\text { forma de convivir } \\
\text { con los pares". }\end{array}$ & $\begin{array}{l}\text { "Divertido y } \\
\text { acogedor, porque } \\
\text { es cosa de ver a } \\
\text { los organizadores y } \\
\text { alumnos". }\end{array}$ \\
\hline
\end{tabular}

Fuente: Elaboración propia de los autores (2016).

\section{Pregunta 2: ¿Qué es lo que te haría más feliz como resultado de esta experiencia?}

Los participantes pertenecientes a las dependencias municipal y particular subvencionado consideran mayoritariamente que serían felices al vivir una experiencia entretenida y de aprendizaje, junto con el hecho de relacionarse de manera positiva con sus pares y generar vínculos de amistad. Con esta tendencia, asociada a los códigos de aspectos generales y vínculos sociales, se observa un $64 \%$ de jóvenes de dependencia municipal y un $63 \%$ de dependencia particular subvencionado. Se observa una diferencia en los sujetos de dependencia particular, quienes valoran el vínculo social en un $40 \%$, asociando homogéneamente sus respuestas en el resto de los códigos. La Tabla 4 entrega las respuestas más destacadas entregadas por los chilevanenses de acuerdo con la dependencia del establecimiento educacional y por código. 
Tabla 4

Respuestas más representativas de los chilevanenses a la pregunta ¿Qué es lo que te haría más feliz como resultado de esta experiencia? Entre paréntesis se indica el porcentaje (\%) de estudiantes que responde por dependencia del establecimiento educacional y por código

\begin{tabular}{|c|c|c|c|c|}
\hline \multirow[b]{2}{*}{ Dependencia } & \multicolumn{4}{|c|}{ Códigos } \\
\hline & $\begin{array}{l}\text { Aprendizaje } \\
\text { científico }\end{array}$ & $\begin{array}{c}\text { Crecimiento } \\
\text { personal }\end{array}$ & $\begin{array}{l}\text { Vínculos } \\
\text { sociales }\end{array}$ & $\begin{array}{l}\text { Aspectos } \\
\text { generales }\end{array}$ \\
\hline Municipal & $\begin{array}{l}\text { "Conocimientos } \\
\text { sobre la ciencia y } \\
\text { biodiversidad, } \\
\text { además de } \\
\text { opiniones de } \\
\text { científicos e } \\
\text { investigadores". } \\
\qquad(21 \%)\end{array}$ & $\begin{array}{l}\text { "Valorar lo que } \\
\text { contiene mi tierra } \\
\text { y preservarlo, } \\
\text { además de } \\
\text { contar lo que } \\
\text { aprendí y crear } \\
\text { conciencia". } \\
\qquad(15 \%)\end{array}$ & $\begin{array}{l}\text { "Que logre } \\
\text { crear } \\
\text { conciencia en } \\
\text { todos y así } \\
\text { podamos lograr } \\
\text { algo que ayude } \\
\text { a la región". } \\
\qquad \mathbf{( 2 8 \% )}\end{array}$ & $\begin{array}{l}\text { "Conocer las } \\
\text { reservas } \\
\text { nacionales". } \\
\text { "Que sea una } \\
\text { experiencia } \\
\text { inolvidable, } \\
\text { divertida y } \\
\text { educativa". } \\
\text { (36\%) }\end{array}$ \\
\hline $\begin{array}{l}\text { Particular } \\
\text { subvencionado }\end{array}$ & $\begin{array}{l}\text { "Conocer la flora } \\
\text { y fauna de mi } \\
\text { región, aprender } \\
\text { sobre el medio } \\
\text { ambiente y saber } \\
\text { de científicos } \\
\text { reconocidos". } \\
\\
\text { (20\%) }\end{array}$ & \begin{tabular}{l} 
"Que esta \\
experiencia me \\
ayude con mi \\
crisis vocacional \\
y que en general \\
sea una buena \\
experiencia, que \\
haya servido \\
darme cuenta si \\
es lo que \\
realmente quiero \\
estudiar". \\
"Poder sacar \\
cosas positivas \\
que me ayuden a \\
colocarlas a \\
prueba en una \\
carrera \\
profesional". \\
\multicolumn{1}{|c}{ (17 \%) }
\end{tabular} & $\begin{array}{l}\text { "Lograr } \\
\text { conocer gente } \\
\text { nueva y } \\
\text { generar un } \\
\text { círculo o red de } \\
\text { personas". }\end{array}$ & $\begin{array}{l}\text { "Lograr un mayor } \\
\text { aprendizaje y } \\
\text { divertirme" } \\
\text { "Aprender algo } \\
\text { nuevo, pasarlo } \\
\text { bien, que me traiga } \\
\text { lindos recuerdos". }\end{array}$ \\
\hline Particular & $\begin{array}{l}\text { "Aprender más } \\
\text { sobre mi entorno, } \\
\text { de la flora y fauna } \\
\text { de mi región, } \\
\text { complementar } \\
\text { mis } \\
\text { conocimientos } \\
\text { sobre la ciencia } \\
\text { conocimiento } \\
\text { nuevo en relación } \\
\text { a las futuras } \\
\text { charlas y } \\
\text { actividades". } \\
\qquad(20 \%)\end{array}$ & $\begin{array}{l}\text { "Aprender y } \\
\text { tomar conciencia } \\
\text { y compromiso } \\
\text { con lo ecológico } \\
\text { y biodiversidad". }\end{array}$ & $\begin{array}{l}\text { "Conocer a } \\
\text { más personas } \\
\text { de mis mismos } \\
\text { intereses y } \\
\text { poder disfrutar } \\
\text { las diferentes } \\
\text { actividades que } \\
\text { están } \\
\text { vinculadas a la } \\
\text { ciencia". }\end{array}$ & $\begin{array}{l}\text { "Aprender y tener } \\
\text { una buena } \\
\text { experiencia". }\end{array}$ \\
\hline
\end{tabular}

Fuente: Elaboración propia de los autores (2016). 


\section{Pregunta 3: ¿En general cómo evalúas este Campamento Chile VA!?}

Al término del campamento, los estudiantes de las tres dependencias valoraron positivamente la experiencia de campamento en general, considerándolo como una experiencia entretenida, interesante, educativa, que permitió un desarrollo equilibrado entre el saber, saber hacer, ser y convivir con otros. De esta forma, el $36 \%$ de los chilevanenses de dependencia municipal, el $31 \%$ de dependencia particular subvencionado y el $77 \%$ de dependencia Particular apuntan sus citas a dicho código.

Por un lado, los estudiantes de establecimientos municipales al inicio de la experiencia declaraban mayoritariamente que imaginaban un campamento entretenido, que ayudaría a sus aprendizajes y a acrecentar en ellos habilidades sociales en vínculo con sus pares. Además en menor medida declararon percibir el campamento como un espacio de aprendizaje científico y desarrollo personal. Finalizada la experiencia, el $39 \%$ de los chilevanenses identifica y valora el aprendizaje científico, junto con el desarrollo personal como un complemento de su sentido social.

Por otro lado, el estudiantado de establecimientos particulares subvencionados por su parte, al inicio de la experiencia, imaginaba en general que se trataría de una actividad entretenida, divertida (31\%), que contribuiría a su aprendizaje científico (24\%). Al término de la esta, confirman que el campamento fue como esperaban (55\%), surgiendo como un aspecto importante para ellos la calidad de la organización del evento y el compromiso del equipo de trabajo en general (21\%).

Asimismo, los de establecimientos particulares al inicio de la experiencia imaginaban que el campamento contribuiría con aprendizaje científico y desarrollo de habilidades científicas, que se transformarían en un aporte en su crecimiento personal y académico. Al termino del campamento realizaron mayoritariamente una positiva valoración general de la experiencia; 77 \% lo identificaron como una experiencia interesante, entretenida, productiva.

La Tabla 5 muestra las respuestas más destacadas entregadas por los chilevanenses de acuerdo con la dependencia del establecimiento educacional y por código. 
Tabla 5

Respuestas más representativas de los chilevanenses a la pregunta ¿En general cómo evalúas este Campamento Chile Va!? Entre paréntesis se indica el porcentaje (\%) de estudiantes que responde por dependencia del establecimiento educacional y por código

\begin{tabular}{|c|c|c|c|c|c|}
\hline & \multicolumn{5}{|c|}{ Códigos } \\
\hline & $\begin{array}{l}\text { Valoración de la } \\
\text { interacción } \\
\text { social }\end{array}$ & $\begin{array}{c}\text { Valoración } \\
\text { de la } \\
\text { organización } \\
\text { v equipo }\end{array}$ & $\begin{array}{l}\text { Valoración del } \\
\text { aprendizaje } \\
\text { científico }\end{array}$ & $\begin{array}{c}\text { Valoración } \\
\text { del desarrollo } \\
\text { personal }\end{array}$ & $\begin{array}{l}\text { Valoración general } \\
\text { de la experiencia }\end{array}$ \\
\hline Municipal & $\begin{array}{l}\text { "Creo que si } \\
\text { debiera poner } \\
\text { una calificación } \\
\text { le pondría un } \\
\text { siete( "), ya que } \\
\text { fue positivos el } \\
\text { trabajo en equipo } \\
\text { y lazos de } \\
\text { amistad". } \\
\text { "Una gran } \\
\text { experiencia } \\
\text { donde todos } \\
\text { éramos como } \\
\text { personas", } \\
\text { (")La escala de } \\
\text { valoración en } \\
\text { Chile es de } 1.0 \text { a } \\
7.0 \text { (14\%) }\end{array}$ & $\begin{array}{l}\text { "Me voy muy } \\
\text { contenta y } \\
\text { agradecida, } \\
\text { puedo decir } \\
\text { que se ha } \\
\text { hecho un gran } \\
\text { trabajo como } \\
\text { organización, } \\
\text { como equipo y } \\
\text { como familia. } \\
\text { Felicitaciones } \\
\text { al equipo de } \\
\text { organización } \\
\text { Chile Va!". }\end{array}$ & $\begin{array}{l}\text { "Lo evaluaría } \\
\text { con una buena } \\
\text { nota, ya que fue } \\
\text { muy educativo y } \\
\text { lleno mis } \\
\text { expectativas, } \\
\text { me marcho con } \\
\text { conocimientos } \\
\text { nuevos gan } \\
\text { muchas ganas } \\
\text { de aplicar lo } \\
\text { aprendido". } \\
\text { "Aprendí } \\
\text { muchas cosas } \\
\text { como aprender } \\
\text { a cuidar la } \\
\text { biodiversidad". } \\
\text { (25\%) }\end{array}$ & $\begin{array}{l}\text { "Como la } \\
\text { mejor } \\
\text { oportunidad } \\
\text { para } \\
\text { desarrollarse } \\
\text { íntegramente, } \\
\text { es decir, una } \\
\text { excelente } \\
\text { experiencia". }\end{array}$ & $\begin{array}{l}\text { "Como una } \\
\text { experiencia única, } \\
\text { totalmente } \\
\text { realizadora tanto en } \\
\text { el ámbito científico } \\
\text { como social". }\end{array}$ \\
\hline $\begin{array}{l}\text { Particular } \\
\text { subvencionad } \\
\text { o }\end{array}$ & $\begin{array}{l}\text { "Muy buena } \\
\text { porque enseñan } \\
\text { muchas cosas, } \\
\text { no solo sobre la } \\
\text { ciencia, también } \\
\text { sobre el trabajo } \\
\text { en equipo y la } \\
\text { convivencia". }\end{array}$ & $\begin{array}{l}\text { "Como una } \\
\text { muy buena } \\
\text { iniciativa para } \\
\text { los jóvenes y } \\
\text { creo que está } \\
\text { muy bien } \\
\text { pensado y } \\
\text { excelentement } \\
\text { e realizado". } \\
\\
\text { (21\%) }\end{array}$ & \begin{tabular}{lr} 
"Lo encontré \\
positivo, una \\
posibilidad \\
únicarrar de \\
conocer $\quad$ un \\
abanicor de \\
cosas por medio \\
de charlas, ya \\
que nos ayudan \\
a entender la \\
naturaleza". \\
\multicolumn{2}{c}{$(\mathbf{2 4} \%)$}
\end{tabular} & \begin{tabular}{l} 
"Lo evalúo \\
como un gran \\
proyecto, una \\
gran \\
oportunidad \\
para las \\
personas de \\
bajos recursos \\
con un \\
potencial". \\
\multicolumn{1}{|c}{$\%)$}
\end{tabular} & $\begin{array}{l}\text { "Me doy la libertad de } \\
\text { decir que el } \\
\text { campamento fue } \\
\text { genial, gratificante, } \\
\text { unido y eso es muy } \\
\text { bueno ya que solo lo } \\
\text { logramos en } 6 \text { días. } \\
\text { De } 1 \text { a } 10 \text { le doy un } \\
11 " . \\
\text { (31 \%) }\end{array}$ \\
\hline Parti & \begin{tabular}{lr} 
"Como un \\
campamento \\
entretenido que \\
logro muchas \\
cosas en tan \\
pocos días $y$ \\
formo lazos de \\
amistad \\
inolvidables. \\
Totalmente \\
supero \\
expectativas". \\
\multicolumn{2}{c}{$(17 \%)$}
\end{tabular} & $\begin{array}{l}\text { Sin respuesta } \\
\text { asociada al } \\
\text { código. }\end{array}$ & $\begin{array}{l}\text { "Lo evalúo } \\
\text { como un } \\
\text { campamento } \\
\text { excelente donde } \\
\text { pude fortalecer } \\
\text { mis } \\
\text { conocimientos". }\end{array}$ & $\begin{array}{l}\text { Sin respuesta } \\
\text { asociada al } \\
\text { código. }\end{array}$ & $\begin{array}{lr} & \text { "En la escala } 1-7 \text { le } \\
\text { doy un } 8 \text {, el personal } \\
\text { fue muchor más } \\
\text { bueno de } r \\
\text { esperado, } & \text { me } \\
\text { encanto". } & \end{array}$ \\
\hline
\end{tabular}

Fuente: Elaboración propia de los autores (2016). 


\section{Pregunta 5: ¿Qué significó Chile VA! para ti? ¿Con qué te vas?}

Para abordar esta consulta por dependencia, se ha considerado el código con mayor cantidad de citas vinculadas. Observando que los estudiantes de dependencia municipal aportan mayor significado a la importancia de las relaciones sociales y la generación de vínculos, busca favorecer la experiencia (38\%). Mantienen el sentido social expresado en sus expectativas.

Los estudiantes de dependencia particular subvencionada inicialmente se inclinaban por expectativas más bien generales, como esperar un campamento divertido, interesante, una experiencia positiva de aprendizaje. Una vez finalizada la experiencia, aportan un mayor significado al desarrollo personal brindado por la iniciativa (37\%).

Inicialmente, los estudiantes de dependencia particular imaginaban un campamento que favoreciera su desarrollo personal, aprendizaje científico y progreso académico. Finalizada la experiencia, identifican y aportan significado a situaciones relacionadas con la generación de vínculos. El sentido social, trabajo en equipo y comprometerse con en conjunto otorga una mirada distinta del aprendizaje científico y de su labor en la sociedad (39 $\%)$.

Si bien en su análisis general los estudiantes en conjunto aportan especial significado a aspectos relacionados con la interacción social, generación de vínculos, como se verá en las citas, se debe mencionar que identifican y dan especial significado al aporte de las ciencias naturales, observando también en estas su carácter social y humano.

La Tabla 6 señala las respuestas más destacadas entregadas por los chilevanenses de acuerdo con la dependencia del establecimiento educacional y por código.

Tabla 6

Respuestas más representativas de los chilevanenses a la pregunta ¿Qué significó Chile Va! para ti? ¿Con qué te vas? Entre paréntesis se indica el porcentaje (\%) de estudiantes que responde por dependencia del establecimiento educacional y por código

\begin{tabular}{|c|c|c|c|c|}
\hline \multirow[b]{2}{*}{ Dependencias } & \multicolumn{4}{|c|}{ Códigos } \\
\hline & $\begin{array}{l}\text { Aprendizaje } \\
\text { científico }\end{array}$ & $\begin{array}{c}\text { Desarrollo } \\
\text { personal }\end{array}$ & $\begin{array}{c}\text { Generación de } \\
\text { vínculos }\end{array}$ & $\begin{array}{c}\text { Positivo en } \\
\text { general }\end{array}$ \\
\hline Municipal & $\begin{array}{l}\text { "Fue la mejor } \\
\text { oportunidad que he } \\
\text { tenido para } \\
\text { interactuar con la } \\
\text { ciencia, me voy } \\
\text { completamente } \\
\text { feliz". } \\
\text { (9\%) }\end{array}$ & 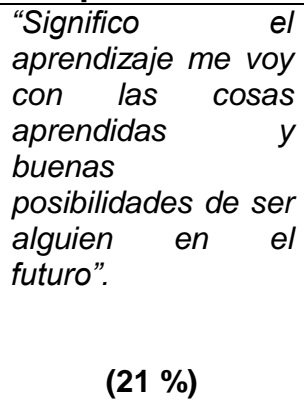 & $\begin{array}{l}\text { "Significo algo } \\
\text { más allá de la } \\
\text { ciencia fue algo } \\
\text { social. Me fui con } \\
\text { lo que aprendí } \\
\text { con las personas". }\end{array}$ & $\begin{array}{l}\text { "Por muy poco } \\
\text { tiempo (1 semana) } \\
\text { de campamento lo } \\
\text { fue todo para mi... } \\
\text { un buen espacio } \\
\text { para vivir, para } \\
\text { desarrollarme, etc... } \\
\text { me voy con amigos y } \\
\text { conocimientos } \\
\text { nuevos". } \\
\text { (32\%) }\end{array}$ \\
\hline
\end{tabular}




\begin{tabular}{|c|c|c|c|c|}
\hline $\begin{array}{l}\text { Particular } \\
\text { subvencionado }\end{array}$ & \begin{tabular}{l} 
"Fue genial!! Ya que \\
a mí me importa \\
mucho la vida, la \\
naturaleza, etc. \\
Todo fue \\
importante, y lo \\
productivo \\
disfrute mucho. Me \\
encanta conocer, \\
me encanta así que \\
fue un placer". \\
"Significó un \\
momento de ver de \\
otra forma la vida \\
natural, me voy con \\
ideas, con gran \\
contenido y las \\
ganas de volver". \\
\multicolumn{4}{c}{ (14) }
\end{tabular} & $\begin{array}{l}\text { "Fue muy } \\
\text { importante, me } \\
\text { ayudo a marcar } \\
\text { más mi futuro, estar } \\
\text { segura de lo que } \\
\text { quiero, me voy con } \\
\text { la mejor vivencia } \\
\text { que he tenido, estoy } \\
\text { muy agradecida". }\end{array}$ & $\begin{array}{l}\text { "Me significó } \\
\text { mucha sabiduría, } \\
\text { aprendí mucho y } \\
\text { voy con ideas } \\
\text { para plantearle a } \\
\text { mi junta de } \\
\text { vecinos". }\end{array}$ & $\begin{array}{l}\text { "Significó mucho } \\
\text { para mí, me voy con } \\
\text { lo mejor que he dado } \\
\text { y la mejor } \\
\text { experiencia vivida". }\end{array}$ \\
\hline Particular & 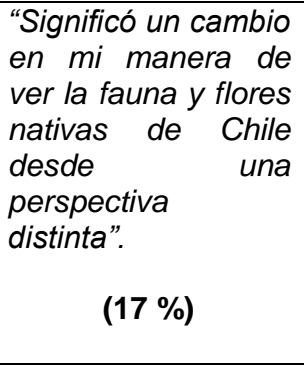 & $\begin{array}{l}\text { "Significó } \\
\text { experiencia mana } \\
\text { bonita agarre cariño } \\
\text { con algunas } \\
\text { personas y me voy } \\
\text { con esperanza de } \\
\text { ser una persona } \\
\text { emprendedora". } \\
\text { (22\%) }\end{array}$ & $\begin{array}{l}\text { "Una experiencia } \\
\text { importante, } \\
\text { aprendí a trabajar } \\
\text { en equipo, me voy } \\
\text { con una nueva } \\
\text { familia". }\end{array}$ & $\begin{array}{l}\text { "Una experiencia } \\
\text { inolvidable y me voy } \\
\text { con los mejores } \\
\text { recuerdos". }\end{array}$ \\
\hline
\end{tabular}

Fuente: Elaboración propia de los autores (2016).

Pregunta 6: ¿Cómo implementarás lo vivido y aprendido en Chile VA! a tu vida? ¿Qué crees que cambiará?

Frente a esta consulta de salida, los estudiantes de dependencia municipal orientan su acción futura en el plano social como agentes generadores de conciencia ambiental. Perciben que su actitud frente a la naturaleza será positiva y que cambiará su relación con la comunidad, $67 \%$ se distribuyen de forma similar entre el plano científico ambiental y plano social.

El $47 \%$ de los estudiantes de dependencia particular subvencionada observan que los principales cambios ocurrirán en su plano personal, siendo más activos en el cuidado de la naturaleza, valorando la biodiversidad desde el plano científico ambiental.

Los estudiantes de dependencia particular, en un $71 \%$, declaran que la experiencia adquirida, aprendizajes y habilidades desarrolladas serán implementados en cambios de actitud personal frente al medioambiente, forma de relacionarse en sociedad al aportar sus conocimientos $\mathrm{y}$, desde el plano científico ambiental, valorar la vida en contacto con la naturaleza, el conocimiento y respeto por el medioambiente. La Tabla 7 muestra las 
respuestas más destacadas entregadas por los chilevanenses de acuerdo con la dependencia del establecimiento educacional y por código.

Tabla 7

Respuestas más representativas de los chilevanenses a la pregunta ¿Cómo implementarás lo vivido y aprendido en Chile Va! a tu vida? ¿Qué crees que cambiará? Entre paréntesis se indica el porcentaje (\%) de estudiantes que responde por dependencia del establecimiento educacional y por código

\begin{tabular}{|c|c|c|c|c|}
\hline \multirow{2}{*}{ Dependencias } & \multicolumn{4}{|c|}{ Códigos } \\
\hline & Plano ambiental & Plano general & $\begin{array}{c}\text { Plano } \\
\text { individual }\end{array}$ & Plano social \\
\hline Municipal & $\begin{array}{l}\text { "Ayudaré } r a \\
\text { preservar todos los } \\
\text { recursos naturales } \\
y \quad \text { claro que } \\
\text { cambiará, porque } \\
\text { todos somos parte } \\
\text { de la } \\
\text { biodiversidad". } \\
\text { (31\%) }\end{array}$ & $\begin{array}{lr}\text { "Obviamente esto } \\
\text { cambia mi forma } \\
\text { de ver algunas } \\
\text { cosas y lo } \\
\text { implementaré a } \\
\text { una mejor calidad } \\
\text { de vida". }\end{array}$ & $\begin{array}{l}\text { "Estoy mucho más } \\
\text { motivada a ayudar } \\
\text { para producir un } \\
\text { cambio positivo y } \\
\text { muchor más } \\
\text { importante, tengo } \\
\text { amigos que me } \\
\text { apoyan. Mirare de } \\
\text { una forma más } \\
\text { 'buena' las cosas } \\
\text { que se me } \\
\text { presentan". } \\
\text { (22\%) }\end{array}$ & $\begin{array}{l}\text { "Cambiará mi actitud } \\
\text { individualista y escucharé } \\
\text { las demás opiniones". } \\
\text { "Yo lo implementaría a la } \\
\text { hora de relacionarme con } \\
\text { otras personas y a trabajar } \\
\text { siempre en equipo, el } \\
\text { campamento en "cierto } \\
\text { modo cambió mi forma de } \\
\text { ver el mundo". } \\
\text { (36 \%) }\end{array}$ \\
\hline $\begin{array}{l}\text { Particular } \\
\text { subvencionado }\end{array}$ & $\begin{array}{l}\text { "Si, intentaré cuidar } \\
\text { al medioambiente y } \\
\text { mi interés por la } \\
\text { naturaleza ahora } \\
\text { es mayor". }\end{array}$ & $\begin{array}{l}\text { "A través de } \\
\text { pequeñas } \\
\text { acciones del día a } \\
\text { día, sí", }\end{array}$ & 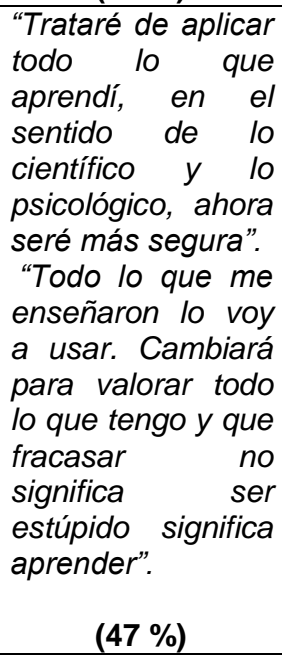 & $\begin{array}{l}\text { "Creo que cambiará la } \\
\text { forma a trabajar en equipo } \\
\text { ya que me di cuenta de que } \\
\text { me sale bien". } \\
\text { "Practicaré la sociabilidad } \\
\text { con las personas que no } \\
\text { son de mis círculos de } \\
\text { amigos". }\end{array}$ \\
\hline Particular & $\begin{array}{l}\text { "Investigar más } \\
\text { sobre los temas } \\
\text { que me gustaron } \\
\text { del campamento". }\end{array}$ & $\begin{array}{l}\text { Sin respuesta } \\
\text { asociada } \\
\text { código. }\end{array}$ & $\begin{array}{lr}\text { "Mi forma de ser y } \\
\text { de pensar cambió } \\
\text { completamente } & \text { lo } \\
\text { que aprendi". } & \\
\text { "Aplicando } & \text { el } \\
\text { liderazgo } & y \\
\text { progresando". } & \end{array}$ & $\begin{array}{l}\text { "Organizando proyectos } \\
\text { que ayuden a la comunidad } \\
\text { donde vivo, la perspectiva } \\
\text { de la gente de mi } \\
\text { comunidad". } \\
\text { "Todo lo aprendido lo voy a } \\
\text { llevar a cabo en mi vida } \\
\text { cotidiana motivando a otros } \\
\text { a hacerlo también. } \\
\text { Cambiará no sólo mi } \\
\text { perspectiva si no que la de } \\
\text { muchos otros también". } \\
\text { (33\%) }\end{array}$ \\
\hline
\end{tabular}

Fuente: Elaboración propia de los autores (2016). 


\subsubsection{Análisis de las bitácoras diarias}

A través del análisis de nube de conceptos, se puede apreciar que los chilevanenses resumen los primeros días de campamento a través de conceptos netamente emocionales, como: interesante, agotador, entretenido. A partir del tercer día, los participantes reflejan el descubrimiento de habilidades blandas, expresadas en conceptos de valoración para las actividades del día, por ejemplo: educativo, informativo, productivo, didáctico, equipo, compañerismo, trascendencia, entre otros (Fig. 1). Con ello, se percibe que el Campamento EXPLORA Chile VA! cumple cabalmente sus objetivos, porque los participantes comienzan a integrar corporalidad, sensibilidad, emocionalidad, afectividad y cognición en función de la adquisición de nuevas habilidades y/o aprendizajes, y en la medida que estos se incorporan, aumentan la autoestima del estudiante y también su apetito cognitivo, condición esencial de todo aprendizaje significativo posible (Álvarez y Vega, 2009; Ausubel, 1963; Ausubel, Novak y Hanesia, 1983; Comisión Nacional del Medio Ambiente, CONAMA, 2009; Escámez y Ortega, 1989; Fuentealba, 2011; Pérez, Pérez y Quijano, 2009).

Al analizar los conceptos científicos aprendidos o reforzados (Figura 2), se aprecia que todos los conceptos que le dan identidad al día formativo tienen directa relación con todas aquellas experiencias y vivencias diseñadas para generar en el estudiante un aprendizaje significativo. Por ejemplo, el día 1 se realizó la actividad "Conversación con maestros, cuyo tópico fue "Chile central como un hotspot de biodiversidad". El día 2, se destacó "Encuentros cercanos: visitas a reservas naturales: Los Ruiles, Altos de Lircay y Federico Albert". El día 3 se apreció una mayor cantidad de conceptos, lo que refleja la diversidad de temas desarrollados en la actividad "Conversación con maestros y charla con joven emprendedor". El día 4 se realizaron las actividades en laboratorio y visita a diferentes departamentos de la UCM. El día 5, los conceptos del manual No Dejes Rastro reflejan las actividades de emprendimiento: geocaching y campaña de forestación. El día 6 los conceptos de polinio y polinizador reflejaron la conversación con científicos, sostenida en la ceremonia de clausura del Campamento EXPLORA Chile VA! Es necesario destacar que todos los conceptos científicos acuñados giran en torno al eje central del campamento, la valoración de la biodiversidad maulina.

De igual manera, es importante señalar que actividades propuestas por el Campamento EXPLORA Chile VA! permiten desarrollar habilidades que facilitan a los chilevanenses el observar y valorar, en este caso la biodiversidad maulina, como algo bello que hay que cuidar. Además, se promueve el desarrollo de actitudes afectivas, pues hay que 
hacerse amigo de esa realidad para defenderla y cuidarla (por ejemplo la actividad de plantación de árboles nativos). Hay que recordar que las habilidades son la base para el desarrollo de competencias profesionales efectivas a futuro (Delors, 1996; Fuentealba, 2011; Tobón, Pimienta y García, 2010).

Figura 1. El día expresado en una palabra o concepto vernacular por los chilevanenses

Día 1
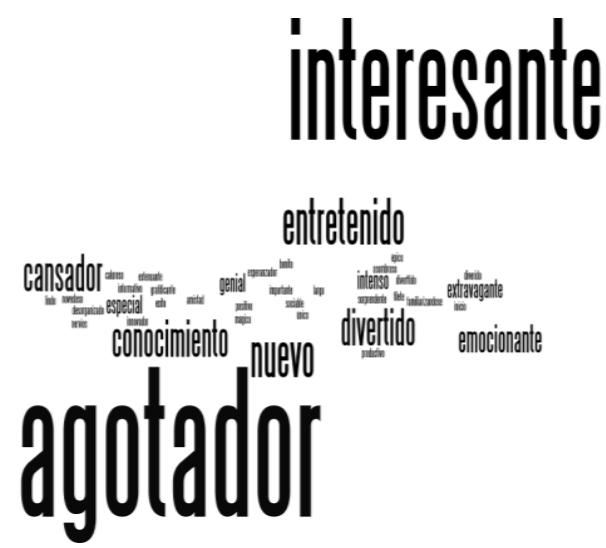

Día 2

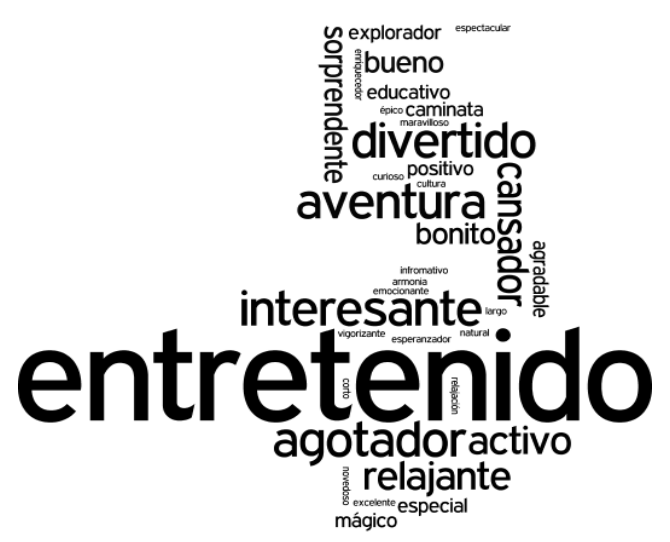

Día 4

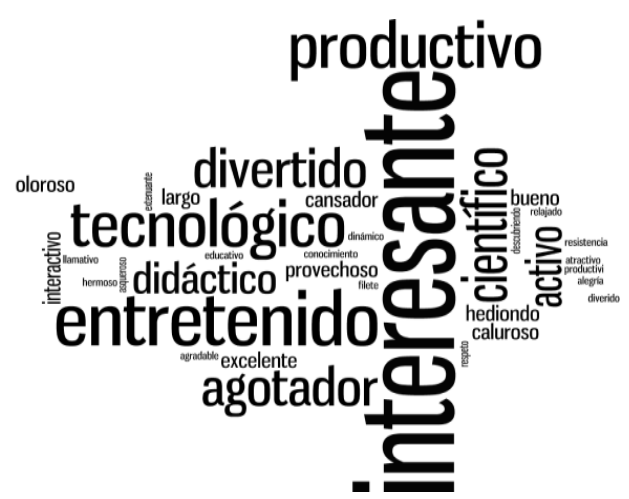


Día 5

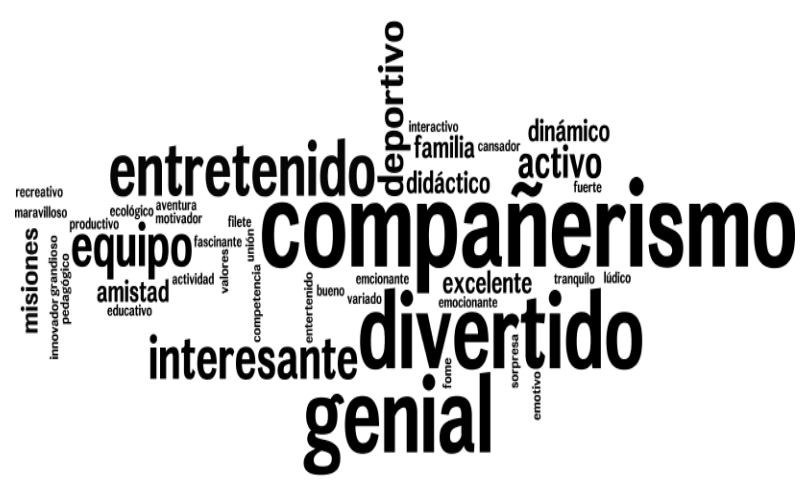

Día 6

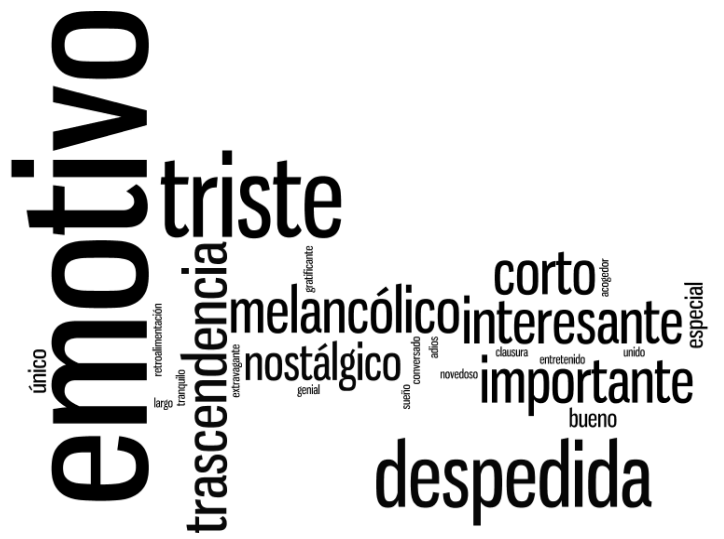

Figura 2. Concepto científico aprendido o reforzado diariamente por los chilevanenes

Día 1

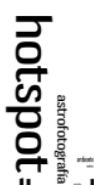

biodiversidad

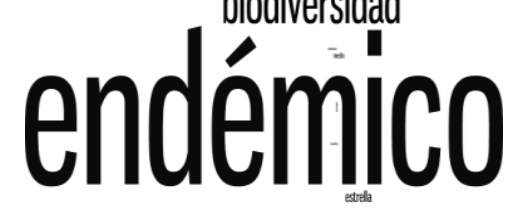

Día 3

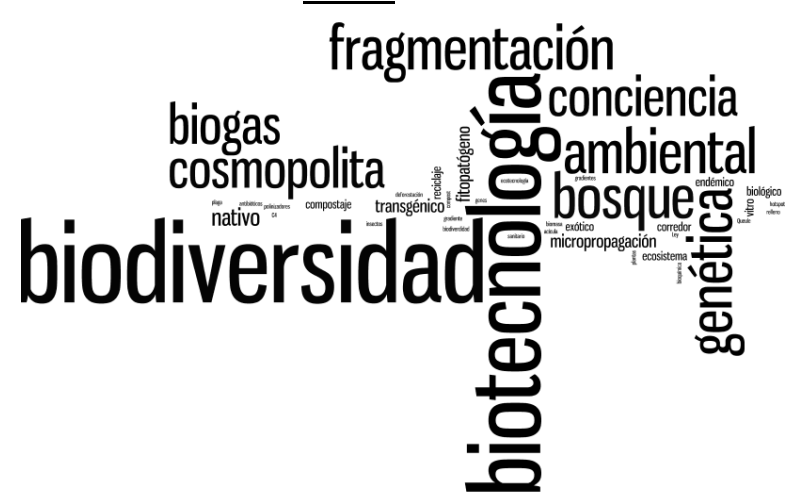

Día 2

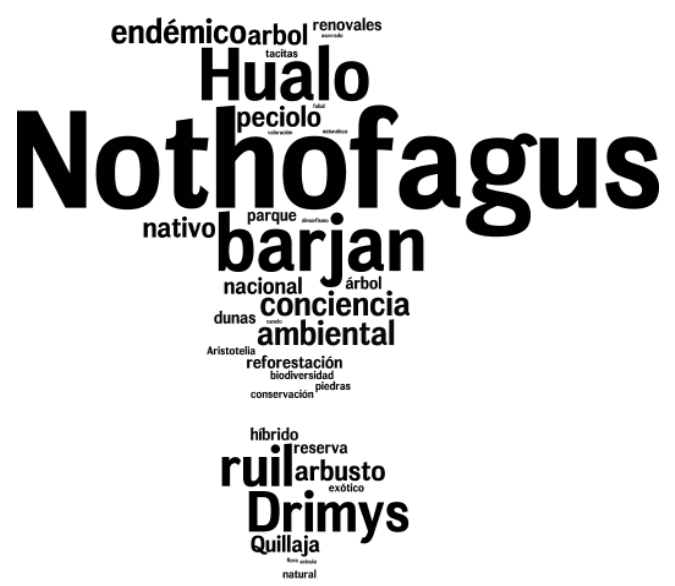

Día 4

proceso-productivo aguas-servidas

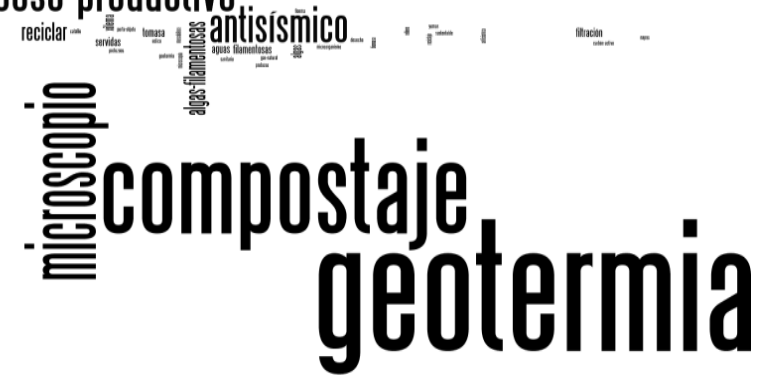


Día 5

EXPLORA

\section{Manual-NDR \\ plantar-árbol \\ pristino}

Día 6

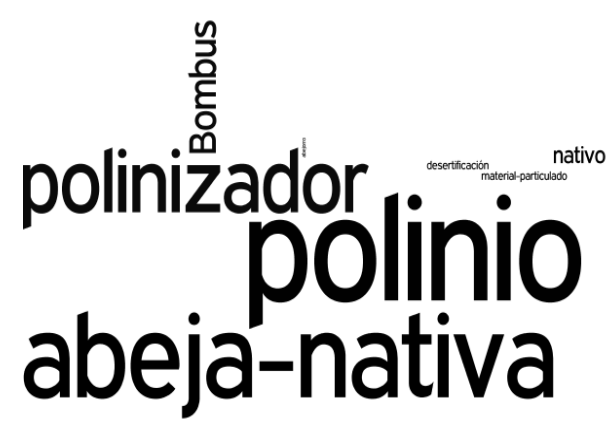

\subsection{Análisis cuantitativo}

\subsubsection{Expectativas de los estudiantes sobre la iniciativa}

Con el objeto de identificar una serie de actitudes y expectativas con respecto a la actividad, se contrastó una serie de afirmaciones con la opinión (grado de acuerdo) de los chivanenses (Tabla 8). Obteniendo alta valoración en las expectativas de los participantes con una media superior a 4, excepto en la aseveración "Chile VA! Será una experiencia

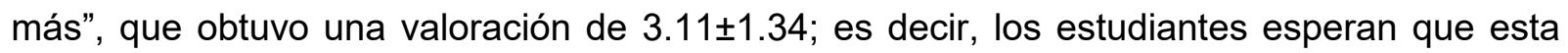
sea una experiencia relevante en su proceso formativo.

Tabla 8

Expectativas de los chilevanenses

\begin{tabular}{lcc}
\hline Criterio / frase* $^{\star}$ & Media & DE \\
\hline Monitor facilitarán la participación & 4.64 & 0.52 \\
Monitor ayudará a mantener el equipo unido & 4.63 & 0.67 \\
Monitor ayudará a mantener el orden en equipo & 4.47 & 0.58 \\
Chile Va! será una experiencia más & 3.11 & 1.34 \\
Movilizadores incentivarán la participación & 4.35 & 0.58 \\
Equipo funcionará bien y se mantendrá unido & 4.39 & 0.67 \\
Intención de aprender junto al equipo & 4.73 & 0.51 \\
Intención de hacer amigos & 4.44 & 0.68 \\
Responsabilidad en mantener la convivencia & 4.60 & 0.59 \\
Responsabilidad en éxito del campamento & 4.42 & 0.66 \\
El campamento será un aporte en conocimiento y habilidades sociales & 4.51 & 0.63 \\
El campamento será una experiencia importante en mi vida & 4.38 & 0.70 \\
Persona emprendedora & 4.24 & 0.85 \\
Persona preocupada por el patrimonio natural & 4.63 & 0.50 \\
Persona que aporte al desarrollo sustentable & 4.05 & 0.83 \\
Persona emprendedora y con conocimientos científicos & 4.21 & 0.77 \\
El campamento cambiará la forma de percibir el mundo & 4.38 & 0.70 \\
\hline
\end{tabular}

*: Escala de Likert de 1 a 5.

Fuente: Elaboración propia de los autores (2016). 


\subsubsection{Impactos de la iniciativa}

Con el objeto de identificar los principales impactos de la actividad, se contrastó una serie de afirmaciones con la opinión (grado de acuerdo) de los participantes, obteniendo alta valoración por parte de los estudiantes del impacto de las actividades del campamento en su proceso de formación, destacando la siguiente aseveración "El campamento fue una experiencia importante en mi vida", con una media de 4.63 \pm 0.6 (Tabla 9).

Tabla 9

Impacto de los chilevanenses

\begin{tabular}{lcc}
\hline Criterio / frase $^{\star}$ & Media & DE \\
\hline Monitor facilitó la participación & 4.89 & 0.31 \\
Monitor ayudó a mantener el equipo unido & 4.92 & 0.30 \\
Movilizadores ayudaron a mantener el orden & 4.72 & 0.47 \\
Movilizadores incentivaron la participación & 4.68 & 0.49 \\
Equipo funcionó bien & 4.76 & 0.54 \\
Equipo trabajó unido & 4.67 & 0.65 \\
Equipo facilitó aprendizaje & 4.82 & 0.49 \\
Nuevos amigos entre los participantes & 4.67 & 0.65 \\
Convivencia con otros equipos fue fácil & 4.82 & 0.49 \\
Todos aportaron para que el campamento fuera exitoso & 4.48 & 0.79 \\
El campamento fue una experiencia importante en mi vida & 4.63 & 0.60 \\
Tengo más herramientas para el futuro & 4.38 & 0.70 \\
En el futuro seré emprendedor apoyado en conocimientos científicos & 4.75 & 0.50 \\
En el futuro estaré preocupado de la protección del patrimonio natural & 4.63 & 0.66 \\
En el futuro aportaré al desarrollo sustentable de mi región & 4.44 & 0.68 \\
\hline
\end{tabular}

*: Escala de Likert de 1 a 5.

Fuente: Elaboración propia de los autores (2016).

\subsubsection{Indicadores asociados a los resultados esperados}

Más del $88 \%$ de los chilevanenses declaró mantener o incrementar su valoración por la ciencia, la protección del patrimonio natural y el aporte al desarrollo sustentable (Tabla 10); de esta manera, se observó un incremento positivo en los indicadores asociados a los objetivos planteados en este Campamento EXPLORA Chile VA!. Es importante señalar que la mantención en esta valoración es del orden del $50 \%$, pues los participantes cuentan con un sello científico, puesto que, dentro de sus establecimientos educacionales, ellos pertenecen a clubes de ciencias y/o participan del área científica. 
Tabla 10

Cambio en las valoraciones de los chilevanenses en torno a la protección del medioambiente, la ciencia y el desarrollo sustentable

\begin{tabular}{|c|c|c|c|c|c|}
\hline \multirow[b]{2}{*}{ Ítem ${ }^{a}$} & \multicolumn{2}{|c|}{ Valor promedio } & \multicolumn{3}{|c|}{ Valoración de los estudiantes (\%) } \\
\hline & Entrada & Salida & Mantienen & Incrementaron & $\begin{array}{l}\text { Mantuvieron o } \\
\text { incrementaron }\end{array}$ \\
\hline $\begin{array}{l}\text { Protección del } \\
\text { patrimonio natural }\end{array}$ & 4.63 & 4.63 & 56.8 & 42.6 & 99.4 \\
\hline $\begin{array}{l}\text { Valoración de la } \\
\text { ciencia desde el } \\
\text { emprendimiento }^{* * \star}\end{array}$ & 4.21 & 4.75 & 50.5 & 48.9 & 99.4 \\
\hline $\begin{array}{ll}\text { Aporte } & \text { al } \\
\text { desarrollo } & \\
\text { sustentable }^{* \star *}\end{array}$ & 4.05 & 4.44 & 46.8 & 41.5 & 88.3 \\
\hline
\end{tabular}

a: Escala de Likert de 1 a $5 ;{ }^{* * *}: p<0.01$.

Fuente: Elaboración propia de los autores (2016).

\section{Conclusiones}

El diseño del Campamento EXPLORA Chile Va! ha sido un espacio educativo científico muy bien pensado y estructurado, ya que posibilitó desarrollar habilidades, actitudes y/o competencias, para las necesidades reales de grupos socioeducativos muy diversos, como son los de dependencia municipal y particular. El Campamento EXPLORA Chile VA! permitió integrar habilidades más allá de las expectativas de los participantes, ya que los resultados muestran que las experiencias de los jóvenes de procedencia municipal tendían al desarrollo social, mientras que para quienes provenían de establecimientos particulares, sus expectativas tendían al incremento de su acervo científico. Transcurridos los seis días de campamento, los chilevanenses de dependencia municipal valoraron considerablemente el incremento de acervo científico como parte de su desarrollo personal; en cambio, los chilevanenses de dependencia particular valoraron enormemente el haber incrementado sus habilidades sociales; esto es, respeto por las diferentes funciones al interior de un equipo de trabajo y/o sentirse parte de un conjunto. Por toda esta información, se infiere que el Campamento EXPLORA Chile VA! sirvió para que todos los participantes, independientemente de su procedencia socio-educativa, descubrieran, desarrollaran e incrementaran habilidades que potenciaran su desarrollo integral.

Evidenciando que el campamento está aportando una complementariedad en la formación de los estudiantes en dimensiones y habilidades que ni ellos mismos esperaban; potenciando emocionalidad, afectividad y cognición en función de nuevas habilidades y/o 
aprendizajes, y en la medida que estos se incorporan, aumentan la autoestima de los jóvenes y su apetito cognitivo, condición esencial de todo aprendizaje significativo posible.

Desde la perspectiva del análisis cuantitativo realizado, se concluye que más del $88 \%$ de los chilevanenses declaró mantener o incrementar su valoración por la ciencia, la protección del patrimonio natural y el aporte al desarrollo sustentable.

Hay que destacar que las variables cualitativas y cuantitativas operaron en forma organizada, es decir, que lo actitudinal operó como base y condición posible de la mayor comprensión y asimilación cognitiva por parte de los jóvenes. Asimismo, que las actividades propuestas por el Campamento EXPLORA Chile VA! permitieron desarrollar habilidades que facilitaron a los chilevanenses a observar, reflexionar y valorar, la biodiversidad maulina, como algo bello y frágil que hay que cuidar, para mantenerlo en el tiempo. Además de promover el desarrollo de habilidades afectivas hacia el medioambiente.

Es importante señalar que este tipo de iniciativa requiere de equipos multidisciplinarios de profesionales y científicos que permitan atender las diversas necesidades de los distintos grupos socioeducativos: formativas, pedagógicas, científicas, técnicas y de interrelación con el medio.

Finalmente, es relevante desarrollar un plan de seguimiento de los chilevanenses, con la finalidad de indagar el recorrido educacional e incremento de vocaciones científicas, además de analizar el impacto del Campamento EXPLORA Chile VA! en la elección de carreras científicas de estos jóvenes.

\section{Agradecimientos}

Los autores agradecen al Programa EXPLORA CONICYT, el cual a través del proyecto CHVA010002 (Campamento EXPLORA Chile Va! Valorando la Biodiversidad Maulina), financió esta iniciativa.

\section{Referencias}

Álvarez, Pedro y Vega, Pedro. (2009). Actitudes ambientales y conductas sostenibles, implicaciones para la educación ambiental. Revista de Psicodidáctica, 14(2), 245-260.

Andreu, Jaime, García-Nieto, Antonio y Pérez, Ana-María. (2007). Evolución de la teoría fundamentada como técnica de análisis cualitativo. Madrid: CIS.

Ascaso, Jorge. (1996). Actividades en la naturaleza. Madrid, España: M.E.C 
Ausubel, David. (1963). The psychology of meaningful verbal learning. New York: Grune and Stratton.

Ausubel, David, Novak, Joseph y Hanesian, Helen. (1983). Psicología educativa: un punto de vista cognoscitivo. [Trad. Mario Sandoval Pineda. Educational psichology. A cognitive view] (2 ${ }^{\text {da }}$ Ed.). México: Editorial Trillas.

Baquedano, Manuel. (2008). Tu huella ecológica. Santiago: Cuatro Vientos.

Bravo, María y Arrieta, José. (2005). El método Dephi. Su implementación en una estrategía didáctica para la enseñanza de las demostraciones geométricas. Revista Iberoamericana de Educación, (35/3), 1-10. Recuperado de http://rieoei.org/inv edu38.htm

Cañadas, Isabel y Sánchez, Alonso. (1998). Categorías de respuesta en escalas tipo Likert. Psicotherma, 10(3), 623-631.

Castillo, Franklin. (2011). Las actividades en la naturaleza en la formación de profesores. Saarbruken: Editorial Académica Española.

Castillo, Franklin. (2015). Necesidades educativas especiales y educación física: Las actividades en la naturaleza como instrumento socializador. Revista Licere. 18(4), 71 93.

Castillo, Franklin y Fuentealba, Marta. (2014). Compendio de buenas prácticas ambientales (Textos de Apoyo a la Docencia. N³2). Talca: Ediciones Universidad Católica del Maule.

Comisión Nacional del Medio Ambiente (CONAMA). (2009). Política Nacional de Educación Para el Desarrollo Sustentable. Santiago: Autor.

Comisión Nacional de Ciencia y Tecnología (CONICYT). (2014). Bases I Concurso de Campamentos de Ciencia, Tecnología e Innovación EXPLORA Chile VA!. Santiago: CONICYT.

Cook, Tomas y Reichardt, Charles. (2004). Métodos Cuantitativos y Cualitativos en investigación Educativa (5 ${ }^{\text {ta }}$ ed.). Madrid: Ediciones Morata.

Delors, Jacques. (1996). La educación encierra un tesoro (Informe a la Unesco de la Comisión Internacional sobre Educación para el siglo XXI). Francia: Ediciones UNESCO.

Duarte, Jakeline. (2003). Ambientes de aprendizaje una aproximación conceptual. Revista Iberoamerica de Educación, 1-18. Recuperado de http://www.rieoei.org/deloslectores/524Duarte.PDF

Escámez, Juan y Ortega, Pedro. (1989). La comunicación en la educación moral y el cambio de actitudes. En Conceptos y Propuestas (Vol. V. Papers d’Educació). Valencia: Nau Llibres. 
Fernández, Astrid y López, Alexander. (2013). Validación mediante método Delphi de un sistema de indicadores para prever, diseñar y medir el impacto sobre el desarrollo local de los proyectos de investigación en el sector agropecuario. Revista Ciencias Técnicas Agropecuarias, 22(3), 1-10. Recuperado de http://scielo.sld.cu/scielo.php?script=sci arttext\&pid=S2071-00542013000300010

Fuentealba, Marta. (2011). Reflexión sobre impacto ambiental antrópico, desarrollo sustentable y educación ambiental. UCMaule-Revista Académica, (41), 29-43.

Fuentealba, Marta. (2014). Actitudes de estudiantes universitarios de la Universidad Católica del Maule frente a temáticas ambientales. Paideia, (55), 119-135. Recuperado de http://www.revistapaideia.cl/

García, Jorge. (2003). Métodos de investigación en educación (Vol. II Investigación educativa). Madrid: UNED.

Goleman, Daniel. (2009). Inteligencia ecológica. Madrid: Kairós.

Guillén, Roberto, Lapetra, Susana y Casterad, José. (2000). Actividades en la naturaleza. Barcelona: INDE.

Hernández, Lidia y Jiménez, Gladys. (2010). Actitudes y comportamiento ambiental del personal del área de conservación marina Isla del Coco, Costa Rica. Biocenosis, 23(1), 2-13. Recuperado http://investiga.uned.ac.cr/revistas/index.php/biocenosis/article/viewFile/1208/1244

Hernández, Roberto, Fernández, Carlos y Baptista, Pilar. (2010). Metodología de la investigación (5ta. ed.). México: Mc Graw Hill.

Luján, Manuel y Rodríguez, Keilyn. (2011). El campamento como programa didáctico: Hacia una propuesta teórico-metodológica para su implementación en los museos. Revista Actualidades Investigativas en Educación, 11(1), 1-33. Recuperado de http://revista.inie.ucr.ac.cr/index.php/aie/article/view/489

Mendieta, Milena y Gutiérrez, Gloria. (2014). Actitudes ambientales hacia el agua, una exploración en estudiantes del Municipio de Ventaquemada (Bocaya). Luna Azul, (39), 40-62.

Recuperado http://www.scielo.org.co/scielo.php?script=sci arttext\&pid=S1909-24742014000200004

Ministerio del Medio Ambiente de Chile. (2009). Política Nacional de Educación para el Desarrollo Sustentable (PNEDS). Recuperado de http://www.sinia.cl/1292/articles46509 recurso 2.pdf

Monroe, Martha y Fien John. (2005). The Role Environmental Education Might Play in the Decade for Education for Sustainable Development. Applied Environmental Education and Communication, 4(3), 203-206.

Ospina, Beatriz, Sandoval, Juan, Aristizábal, Carlos y Ramírez, Martha. (2005). La escala de Likert en la valoración de los conocimientos y las actitudes de los profesionales de 
enfermería en el cuidado de la salud. Antioquia. Investigación y Educación en Enfermería, 23(1), 14-29.

Pereira-Pérez, Zulay. (2011). Los diseños de método mixto en la investigación en educación: Una experiencia concreta. Revista Electrónica Educare, 15(1), 15-29. Recuperado de http://www.redalyc.org/articulo.oa?id=194118804003

Pérez, Miguel-Angel; Pérez, Miguel y Quijano, Rocío. (2009). Valoración del cambio de actitudes hacia el medio ambiente producido por el programa didáctico "EICEA" en los alumnos de Educación Secundaria Obligatoria (14-16 años). Revista Electrónica de Enseñanza de las Ciencias, 8(3), 1019-1036.

San Martín, Daniel. (2014). Teoría fundamentada y Atlas.ti: recursos metodológicos para la investigación educativa. Revista Electrónica de Investigación Educativa, 16(1) ,103122. Recuperado de http://redie.uabc.mx/vol16no1/contenido-sanmartin.html

Sosa, Susana, Isaac-Márquez, Ricardo, Eastmond, Amarella, Ayala, María y Arteaga, Marco. (2010). Educación superior y cultura ambiental en el sureste de México. Universidad y Ciencia, 26(1) ,33-49.

Tikka, Paivi, Kuitunen, Markku y Tynys, Salla. (2000). Effects of educational background on students attitudes, activity levels, and knowledge concerning the environment. Journal of Environmental Education, 31(3), 12-19.

Tobón, Sergio, Pimienta, Julio y García, Juan. (2010). Secuencias didácticas: aprendizaje y evaluación de competencias. México: Pearson.

Vasconcelos, Carlos y Praia, Félix. (2005). Aprendizaje en contextos no formales y alfabetización científica. Alambique. Didáctica de las Ciencias Experimentales, (43), 6773.

Zúñiga, Miguel y Fuentealba, Marta. (2001). Sustentabilidad, ecología industrial y capitalismo natural. UCMaule, Revista Académica, (27), 7-16. 